\title{
Elaboration of a Wind Energy Potential Map in Morocco using GIS and Analytic Hierarchy Process
}

\author{
Fatma Elmahmoudi \\ SSDIA Laboratory \\ ENSET Mohammedia Hassan 2 \\ University \\ Casablanca, Morocco \\ fatmaelmahmoudi@gmail.com
}

\author{
Oum El Kheir Abra \\ GRIEF Team \\ Regional Center for Education and \\ Training Professions \\ Rabat, Morocco \\ abra.oek@gmail.com
}

\author{
Abdelhadi Raihani \\ SSDIA Laboratory \\ ENSET Mohammedia Hassan 2 \\ University \\ Casablanca, Morocco \\ abraihani@yahoo.fr
}

\author{
Ouafae Serrar \\ GRIEF Team \\ Regional Center for Education and Training Professions \\ Marrakech, Morocco \\ serrar.ouafae@gmail.com
}

\author{
Lhoucine Bahatti \\ SSDIA Laboratory \\ ENSET Mohammedia Hassan 2 University \\ Casablanca, Morocco \\ lbahatti@gmail.com
}

\begin{abstract}
The construction of a wind power generation center starts by the selection of a suitable wind farm location. The selection includes six factors, namely wind speed, slope, land use, distance from the power lines, distance from the roads, and distance from populated areas which have been integrated into QGIS by weights calculated using the Analytical Hierarchy Process (AHP) approach. As a result of this study, the areas having very high wind potentiality have been identified and a best wind farm location map has been prepared. The map, using the overlay function in GIS, exhibits the most and least suitable areas for the location of wind farms in Morocco. The approach could help identify suitable wind farm locations in other areas using their geographic information.
\end{abstract}

Keywords-Analytical Hierarchy Process (AHP); MultiCriteria Decision Making (MCDM); Geographic Information System (GIS); wind farms; renewable energy

\section{INTRODUCTION}

Electric energy production is an important factor for the economic growth of any country. Globally, fossil fuels are the main resource for electric energy production, but there are not unlimited, they pollute the environment, and their prices vary. The use of renewable energy, especially wind power, to generate electricity is a relevant solution because it has advantages such as low pollution and very low prices [1-3]. Morocco has great resources for renewable energy exploitation. Due to its geographical position, it has a good potential of wind energy development to cover the increasing energy demand. Morocco has a goal of exploiting renewable energy by increasing wind energy production to satisfy the increasing demand. The research of a suitable location for wind farm setting [4] is crucial because it encloses different criteria such as wind speed, land cover, slope, distance to urban places and roads around the candidate area. In order to have an optimal location, site selection analysis [5] is the best solution to find these sites. As a result, the suitability of a wind farm location is subject to multiple decision criteria [6].

For this purpose, two decision tools, Geographic Information Systems (GIS) and Multiple Criteria Decision Analysis (MCDA) [7] were utilized to identify suitable sites for wind farms [5]. Applying GIS-based Analytic Hierarchy Process (AHP) approach is meant to specify and classify the criteria, to identify the suitable and unsuitable locations for each layer in a GIS, and calculate the weights using AHP [8] to create the final map of wind farm suitability in Morocco. The aim of this work is to provide decision makers with a tool for the implementation projects of new turbines [9].

\section{STUDY AREA}

The Kingdom of Morocco is located in the north-west of the African continent. It is bordered by the Atlantic Ocean on the West, the Mediterranean Sea on the North, Algeria on the East, and Mauritania on the South. Its total area is $710850 \mathrm{~km}^{2}$, the lowest point is $-55 \mathrm{~m}$ (Sebkha Tah) and the highest is $4144 \mathrm{~m}$ (Toubkal summit). Morocco has an estimated population of 34 million people, mostly concentrated in the northwest. The North of the country is covered mostly by forests. In the South, bare areas are the dominant land cover. Morocco has good climatic conditions for the installation of wind farms. Morocco has a large surface where wind speed can reach up to $8 \mathrm{~m} / \mathrm{s}$. The methodology developed in this section is applied to evaluate the suitability of wind farms in Morocco.

\section{MCDM AND GIS METHODOLOGY}

\section{A. Identification of Decision Criteria and Constraints}

The wind farm planning process [10] often incorporates complexity, uncertainty, multiple management objectives, and various spatial data attributes. Moreover, in order to assess the degree of suitability for a certain potential location, most 
decision-making processes generally consider multiple criteria. In this study, decision criteria consist of constraints representing quantifiable attributes to assist the decisionmaking process. Moreover, the overall objective of the decision criteria identified in this study is to evaluate wind farm site suitability based on different types of criteria (Figure 1). The criteria were established based on previous scientific publications and the current legislative framework in Morocco as described below.

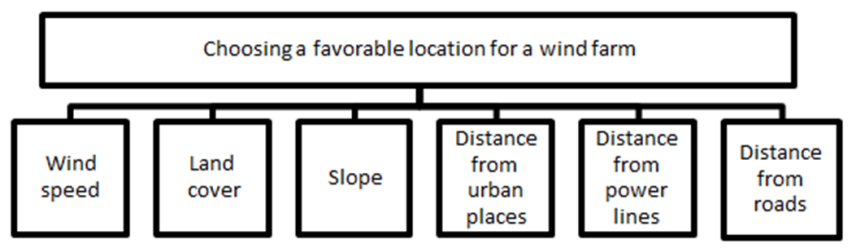

Fig. 1. Hierarchy structure.

\section{1) Data Collection}

In order to reach an accurate and reliable estimation of the wind power potential in of Morocco, proper data should be collected, modified and analyzed. Several data sources have been utilized, not only for wind speed, but also for land cover, slope, urban areas, power lines, and road proximity. To determine the different classification potential for wind energy in Morocco, several satellite images and traditional data sets have been garnered from IRENA global map atlas [11]. The Shuttle Rader Topographic Mission (SRTM) Digital Elevation Model (DEM) of $30 \mathrm{~m}^{2}$ resolution has been processed in QGIS 2.18.3 software for the preparation of the slope map [12]. The roads and the power lines have been developed by using open street map tools in QGIS [13]. By using the buffer tools, distances from urban areas, roads, and power lines have been assessed. Landsat 8 satellite images of Morocco have been obtained from its official website [14]. All the layers have been converted into raster format, reclassified and the weight of each layer was calculated with the AHP method [15]. Table I shows the information about wind farm suitability criteria.

TABLE I. DATA SOURCES

\begin{tabular}{|c|c|c|}
\hline Criteria & Data sources & $\begin{array}{c}\text { Original data } \\
\text { structure }\end{array}$ \\
\hline Wind speed & IRENA global map Atlas & Raster \\
\hline Land cover & Landsat 8 satellite images & Raster \\
\hline Slope & Digital Elevation Model (DEM) & Raster \\
\hline Urban area & Open street map & Vector \\
\hline Distance to power lines & Open street map & Vector \\
\hline Distance to roads & Open street map & Vector \\
\hline
\end{tabular}

\section{2) Decision Criteria}

Choosing the best wind farm location depends on several factors [16]. The combined assessment of those factors using modern techniques can provide a detailed picture of this location. The selection of criteria began with a literature review to reduce the criteria deemed relevant and critical for the adequacy of a wind farm facility. In this paper, a total of 6 criteria are considered for modeling the suitability of wind farm locations in Morocco.

\section{a) Wind Speed}

In the field of selecting the best location of wind energy, according to the experts' opinion, wind speed is the most important criterion to consider when building a wind energy plant site. Authors in [17] applied the wind speed data at various heights through various probability distribution functions and got as a result that the Rayleigh distribution function is the best for finding site selection. Regions with higher wind speed generally have higher potentiality for wind farm installation. The wind speed in Morocco varies depending on location (Figure 2 )[11].

\section{b) Land Cover}

Land cover or land use is one of the most important criteria for energy investments. Wind farms should be installed outside protected areas, wetlands, aquatic and forest areas. The study area is classified into five categories of land use practices (Figure 3) [14].

\section{c) Slope}

Slope has a direct relationship with construction and maintenance costs. As the gradient becomes higher, the costs of construction and maintenance also become higher. As a result, areas with higher slopes are generally considered less suitable (Figure 4) [12].

\section{d) Distance from Urban Places}

This is a very important criterion in wind farm siting. Distance from populated areas is an important geomorphic factor that should be considered. As a result, regions far from urban places are having higher index of suitability [18]. In this paper, the distance from populated areas is prepared in QGIS by using the buffer tool multiple times, from residential areas to avoid noise and nuisance, and later, a single vector has been created and converted to the raster image (Figure 5) [13].

\section{e) Distance from Power Lines}

When choosing a favorable location for a wind farm, it is necessary to take into account the availability of transmission lines between the wind farms and the electricity grid to reduce the cost related to cabling and electricity losses [19]. Wind farms should be sited in the close vicinity of the electricity grid (Figure 6) [13].

\section{f) Distance from Roads}

To minimize cost, it is important that the wind farm should be near the road for the easier transmission of the installation and maintenance equipment (Figure 7). In most wind farm siting assessments, the areas closer to roads are considered more suitable. However, there is not an exact optimum value of distance from the wind turbines to the road. In our study, we considered different buffer distances (Table II).

\section{3) Decision Constraints}

In this study, each criterion has a number of constraints which are identified, discussed, and summarized in Table II.

\section{a) Wind Speed}

Wind turbines start producing electricity at around $4 \mathrm{~m} / \mathrm{s}$. In this study, the wind speed was reclassified into 5 classes: 0 $3 \mathrm{~m} / \mathrm{s}, 3-5 \mathrm{~m} / \mathrm{s}, 5-6 \mathrm{~m} / \mathrm{s}, 6-7 \mathrm{~m} / \mathrm{s}$, and above $7 \mathrm{~m} / \mathrm{s}$. The areas with 
a wind speed lower than $4 \mathrm{~m} / \mathrm{s}$ were considered unfeasible for wind farm development. In Figure 2 the wind speed map is exhibited. The data used are from [11].

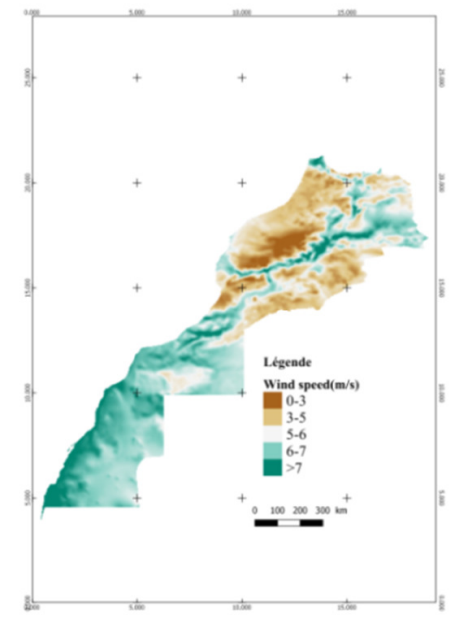

Fig. 2. Wind map. Data taken from [11].

b) Land Use

In this study, the land cover was reclassified into 5 classes: water area, forest, shrub land, tree land, and bare area. In these cases the first class represented unsuitable areas for location of wind farms due to environmental reasons and the remaining classes represented increasing suitability.

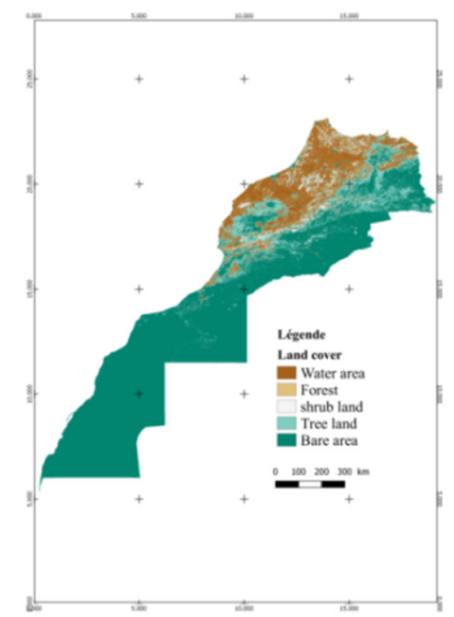

Fig. 3. Land cover map. Data taken from [14].

\section{c) Slope}

For economic reasons, wind farms should be located in flat areas. In this study the slope was reclassified into 5 classes: $<25 \mathrm{~m}, 25-650 \mathrm{~m}, 650-1250 \mathrm{~m}, 1250-2000 \mathrm{~m}$ and $>2000 \mathrm{~m}$. The class representing flat areas $(<25 \mathrm{~m})$ has been judged as the most suitable and the other areas as the least suitable.

\section{d) Distance from Urban Areas}

Previous scientific publications detail various distances from urban areas. For this study, we create new feature classes from the dataset representing populated areas that included multiple buffer zones: $0-10 \mathrm{~km}, 10-15 \mathrm{~km}, 15-20 \mathrm{~km}, 20-25 \mathrm{~km}$ and $>25 \mathrm{~km}$ around these areas. In these cases the first buffer zone represented unsuitable areas for wind farm positioning according to safety reasons and the other buffer zones represented decreasing suitability.

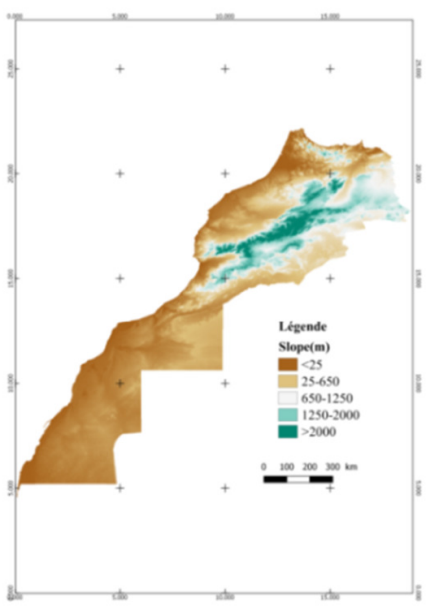

Fig. 4. Slope constraints map. Data taken from [12]

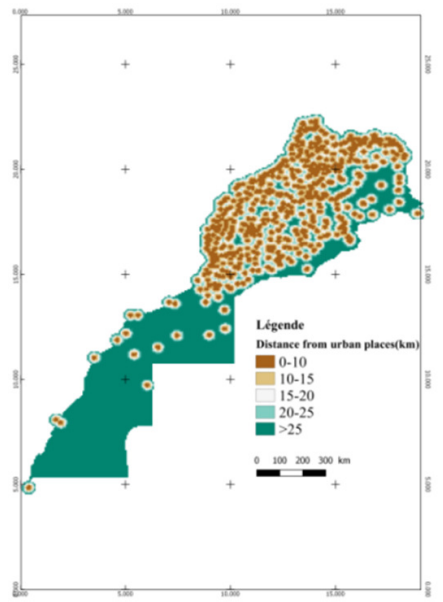

Fig. 5. Distance from urban areas. Data from [13].

e) Distance from Power Lines

For economic reasons, wind farms should be located in close proximity to power lines. As a result in our study we create new feature classes of the distance from power lines that included multiple buffer zones: $0-5 \mathrm{~km}, 5-10 \mathrm{~km}, 10-15 \mathrm{~km}, 15-$ $20 \mathrm{~km}$ and $>20 \mathrm{~km}$ around these areas. The first buffer zone represents the most suitable areas for wind farm positioning according to economic reasons and the other buffer zones represented increasing unsuitability.

\section{f) Distance from Roads}

For the purpose of this study, we created new feature classes that included multiple buffer zones: $0-5 \mathrm{~km}, 5-10 \mathrm{~km}$, $10-15 \mathrm{~km}, 15-20 \mathrm{~km}$ and $>20 \mathrm{~km}$ around these areas. The first 
buffer zone represents the most suitable areas for wind farm positioning due to economic and accessibility reasons and the remaining buffer zones represented increasing unsuitability.

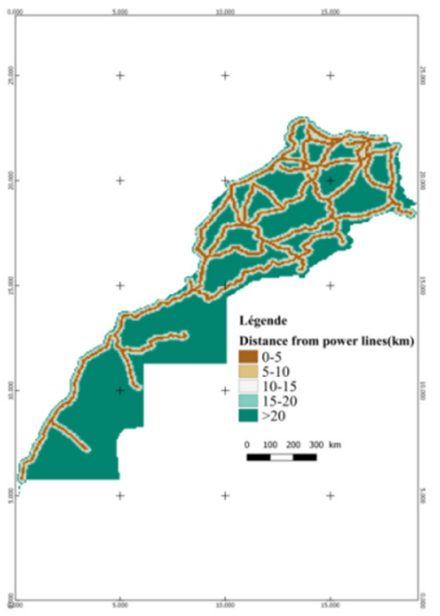

Fig. 6. Distance from power lines. Data from [13].

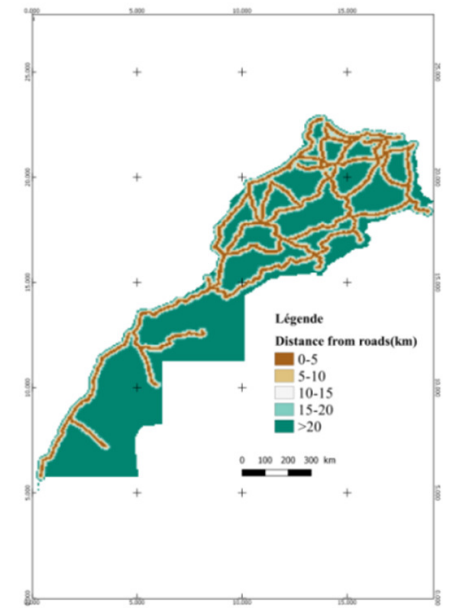

Fig. 7. Distance from roads. Data from [13]

\section{B. Reclassification of Criteria}

\section{1) Simple Reclassification of Criteria}

Decision constraints are based on a scale rating aim to exclude areas deemed 'unfeasible' for wind farm development. Therefore, unfeasible areas are denoted a value equal to 0 whilst feasible areas are denoted a value ranging from 1 to 4 . The complete classification is presented in Table II, where $A_{1}, A_{2}, A_{3}, A_{4}, A_{5}, A_{6}$ are Wind speed (m/s), Land cover, Slope $(\mathrm{m})$, Distance from urban places $(\mathrm{km})$, Distance from power lines $(\mathrm{km})$ and Distance from roads $(\mathrm{km})$ respectively.

\section{2) AHP Reclassification of Criteria}

The AHP model has been applied to determine weights and ranks of all the subcategories of different parameters for the purpose of finding suitable wind farm locations. The complete classification is presented in Table III. The selection of the best location of wind farm can be expressed as:

$$
S L=\sum_{i=1}^{n} W_{i} \times R_{i}
$$

where $S L$ is the suitable location index, $W_{i}$ is the weight of each parameter, and $R_{i}$ is the rating of the classified values under a parameter. Using the SL model, we can classify the final map into five classes of very low, low, moderate, high and very high potentiality.

TABLE II. RATING SCHEME FOR MULTIPLE MODELING CRITERIA

\begin{tabular}{|c|c|c|c|c|c|c|}
\hline $\mathbf{R i}$ & $\boldsymbol{A}_{\boldsymbol{1}}$ & $\boldsymbol{A}_{2}$ & $\boldsymbol{A}_{3}$ & $\boldsymbol{A}_{4}$ & $\boldsymbol{A}_{5}$ & $\boldsymbol{A}_{\boldsymbol{6}}$ \\
\hline $\begin{array}{c}\text { Very high } \\
(\mathbf{4})\end{array}$ & $>7$ & $\begin{array}{c}\text { Bare } \\
\text { area }\end{array}$ & $<25$ & $>25$ & $(0,5)$ & $(0,5)$ \\
\hline High (3) & $(6,7)$ & $\begin{array}{c}\text { Tree } \\
\text { land }\end{array}$ & $(25,650)$ & $(20,25)$ & $(5,10)$ & $(5,10)$ \\
\hline $\begin{array}{c}\text { Moderate } \\
(\mathbf{2})\end{array}$ & $(5,6)$ & $\begin{array}{c}\text { Shrub } \\
\text { land }\end{array}$ & $(650,1250)$ & $(15,20)$ & $(10,15)$ & $(10,15)$ \\
\hline Low (1) & $(3,5)$ & Forest & $(1250,2000)$ & $(10,15)$ & $(15,20)$ & $(15,20)$ \\
\hline $\begin{array}{c}\text { Very low } \\
(\mathbf{0})\end{array}$ & $(0,3)$ & $\begin{array}{c}\text { Water } \\
\text { area }\end{array}$ & $>2000$ & $(0,10)$ & $>20$ & $>20$ \\
\hline
\end{tabular}

\section{GIS Analysis and MCDA}

Spatial decision making is often a process characterized by complexity, uncertainty, multiple and sometimes conflicting management goals, and the integration of different types of data. A decision is an assessment of suitability of a location. In this research, a number of siting criteria are used to apply an integrated approach of two decision tools, the Geographic Information Systems (GIS) and the Multiple Criteria Decision Analysis (MCDA) [20]. The suitability analysis aims to identify the most appropriate sites for wind power development. The overall procedure uses spatially referenced data to create a decision map of suitable locations in QGIS. All map layers have been converted to grid data. This section explains our analysis step-by-step.

\section{1) Integration of GIS Analysis and MCDA}

The solution of spatial decision problems is the combination between geographic and decision data to get a decision. GIS is the analysis and modelling of geographic data to solve complex decision problems. Open source software Quantum Geographic Information System (QGIS) is our tool of implementation, analysis, and incorporation of different types of data. MCDA is a famous decision making instrument. It is used to make decisions in a multi-criteria situation [21]. It computes the weights of the criteria and the position of alternatives. The integration of GIS-MCDA means to use GIS to prepare layers for the multi-criteria method by calculating the contribution of each layer in the final map to be viewed in GIS. A variety of MCDA methods exists that can be used for various purposes such as choosing, ranking, or sorting. The decision maker usually decides which method to be used by taking the nature of the problem into consideration. Authors in [22] calculated the potential for biodiesel production from plant sources, in this region using GIS software. Authors in [23] applied GIS and AHP methods in order to provide suitable sites for the construction of sanitary landfills in Johor Bahru, Malaysia and authors in [24] utilized AHP to provide an accurate result for flood mapping. 
TABLE III. SUB-CRITERIA OF EACH PARAMETER AND THEIR WEIGHTS

\begin{tabular}{|c|c|c|c|c|c|c|c|c|}
\hline Criteria & & & Sul & riteria & & & Sub-criteria weight & Criteria weight \\
\hline \multirow{6}{*}{$A_{1}$} & & $>7$ & $(6,7)$ & $(5,6)$ & $(3,5)$ & $(0,3)$ & $\boldsymbol{R}_{i}$ & $W_{i}$ \\
\hline & $>7$ & 1 & 2 & 4 & 6 & 8 & 0.459 & \multirow{5}{*}{0.427} \\
\hline & $(6,7)$ & & 1 & 2 & 4 & 6 & 0.261 & \\
\hline & $(5,6)$ & & & 1 & 2 & 5 & 0.146 & \\
\hline & $(3,5)$ & & & & 1 & 4 & 0.097 & \\
\hline & $(0,3)$ & & & & & 1 & 0.037 & \\
\hline \multirow{6}{*}{$A_{2}$} & & Bare area & Tree land & Shrub land & Forest & Water area & $\boldsymbol{R}_{i}$ & $W_{i}$ \\
\hline & Bare area & 1 & 3 & 5 & 7 & 9 & 0.508 & \multirow{5}{*}{0.089} \\
\hline & Tree land & & 1 & 2 & 5 & 7 & 0.241 & \\
\hline & Shrub land & & & 1 & 3 & 5 & 0.142 & \\
\hline & Forest & & & & 1 & 4 & 0.075 & \\
\hline & Water area & & & & & 1 & 0.034 & \\
\hline \multirow{6}{*}{$A_{3}$} & & $<25$ & $(25,650)$ & $(650,1250)$ & $(1250,2000)$ & $>2000$ & $\boldsymbol{R}_{i}$ & $W_{i}$ \\
\hline & $<25$ & 1 & 3 & 5 & 7 & 8 & 0.489 & \multirow{5}{*}{0.207} \\
\hline & $(25,650)$ & & 1 & 4 & 5 & 7 & 0.276 & \\
\hline & $(650,1250)$ & & & 1 & 3 & 5 & 0.13 & \\
\hline & $(1250,2000)$ & & & & 1 & 3 & 0.068 & \\
\hline & $>2000$ & & & & & 1 & 0.036 & \\
\hline \multirow{6}{*}{$\boldsymbol{A}_{4}$} & & $>25$ & $(20,25)$ & $(15,20)$ & $(10,15)$ & $(0,10)$ & $\boldsymbol{R}_{i}$ & $W_{i}$ \\
\hline & $>25$ & 1 & 3 & 5 & 7 & 9 & 0.491 & \multirow{5}{*}{0.033} \\
\hline & $(20,25)$ & & 1 & 3 & 7 & 9 & 0.287 & \\
\hline & $(15,20)$ & & & 1 & 3 & 4 & 0.12 & \\
\hline & $(10,15)$ & & & & 1 & 4 & 0.07 & \\
\hline & $(0,10)$ & & & & & 1 & 0.033 & \\
\hline \multirow{6}{*}{$A_{5}$} & & $(0,5)$ & $(5,10)$ & $(10,15)$ & $(15,20)$ & $>20$ & $\boldsymbol{R}_{i}$ & $W_{i}$ \\
\hline & $(0,5)$ & 1 & 2 & 4 & 6 & 8 & 0.452 & \multirow{5}{*}{0.175} \\
\hline & $(5,10)$ & & 1 & 3 & 4 & 6 & 0.281 & \\
\hline & $(10,15)$ & & & 1 & 3 & 5 & 0.151 & \\
\hline & $(15,20)$ & & & & 1 & 3 & 0.078 & \\
\hline & $>20$ & & & & & 1 & 0.039 & \\
\hline \multirow{6}{*}{$A_{6}$} & & $(0,5)$ & $(5,10)$ & $(10,15)$ & $(15,20)$ & $>20$ & $\boldsymbol{R}_{i}$ & $W_{i}$ \\
\hline & $(0,5)$ & 1 & 2 & 4 & 6 & 8 & 0.453 & \multirow{5}{*}{0.068} \\
\hline & $(5,10)$ & & 1 & 2 & 5 & 7 & 0.278 & \\
\hline & $(10,15)$ & & & 1 & 3 & 5 & 0.158 & \\
\hline & $(15,20)$ & & & & 1 & 3 & 0.074 & \\
\hline & $>20$ & & & & & 1 & 0.038 & \\
\hline
\end{tabular}

In the current study GIS and AHP methods were applied. The detailed steps are described in our previous paper [25].

\section{2) AHP Model.}

As mentioned in the previous sections, 6 layers of data which are related to the construction of wind power stations were considered. All the layers are classified using a rating scale (Table II) and AHP scale (Table III) in the QGIS. Once the map layers were generated, a pairwise comparison matrix has been built in which the diagonal elements are equal to 1 (Table IV). For instance, the first row represents the significance of wind speed when compared to the other six parameters positioned in the column. In the pairwise comparison matrix, the rows follow the inverse value of each factor and its significance with other (e.g. the wind speed is little more important than the land use and slope, hence, the value of wind speed is 1 and other two factors are 5 and 4, thus in the next row land use and slope in having a value of $1 / 5$ and $1 / 4$ respectively and so on). After the preparation of all the thematic layers, the analytical hierarchy process model has been applied to give different weights (Table V) to the considered parameters [26]. The factors controlling the wind farm selection of our area are wind speed, slope, distance from the power line, distance from roads, and distance from urban areas.

TABLE IV. PAIRWISE MATRIX

\begin{tabular}{|l|l|l|l|l|l|l|}
\hline & $\boldsymbol{A}_{\boldsymbol{1}}$ & $\boldsymbol{A}_{\mathbf{2}}$ & $\boldsymbol{A}_{3}$ & $\boldsymbol{A}_{\mathbf{4}}$ & $\boldsymbol{A}_{5}$ & $\boldsymbol{A}_{\boldsymbol{6}}$ \\
\hline $\boldsymbol{A}_{\boldsymbol{1}}$ & 1 & 5 & 4 & 8 & 3 & 6 \\
\hline $\boldsymbol{A}_{\boldsymbol{2}}$ & & 1 & $1 / 4$ & 4 & $1 / 3$ & 2 \\
\hline $\boldsymbol{A}_{3}$ & & & 1 & 4 & 3 & 2 \\
\hline $\boldsymbol{A}_{\boldsymbol{4}}$ & & & & 1 & $1 / 6$ & $1 / 3$ \\
\hline $\boldsymbol{A}_{5}$ & & & & & 1 & 4 \\
\hline $\boldsymbol{A}_{\boldsymbol{6}}$ & & & & & & 1 \\
\hline
\end{tabular}

TABLE V. WEIGHT OF CRITERIA

\begin{tabular}{|c|c|c|c|c|c|c|}
\hline & $\boldsymbol{A}_{1}$ & $\boldsymbol{A}_{2}$ & $\boldsymbol{A}_{3}$ & $\boldsymbol{A}_{4}$ & $\boldsymbol{A}_{5}$ & $\boldsymbol{A}_{\mathbf{6}}$ \\
\hline $\boldsymbol{W}_{\boldsymbol{i}}$ & 0.427 & 0.089 & 0.207 & 0.033 & 0.175 & 0.068 \\
\hline
\end{tabular}

Multiplication of the classified layers with their associated weights was carried out during the AHP method. All the weighted grid layers were added together in the Easy AHP Tool in QGIS to get the final suitability map. The final grid layer has been classified into five classes: very low, low, moderate, high, and very high suitability for wind farm development in Morocco based on the criteria and their calculated weights (Figures 8,9). 


\section{RESUlts}

\section{A. Decision Constraints Analysis}

This study's objective was to determine suitable wind farm locations in Morocco. The criteria were selected from different sources reflecting different considerations. The impact of each criterion in the suitability of wind farms was identified. Most data were available in vector format and were converted into grid. The vector layers needed more complex operations such as distance calculations for the factors using Calculator Raster.

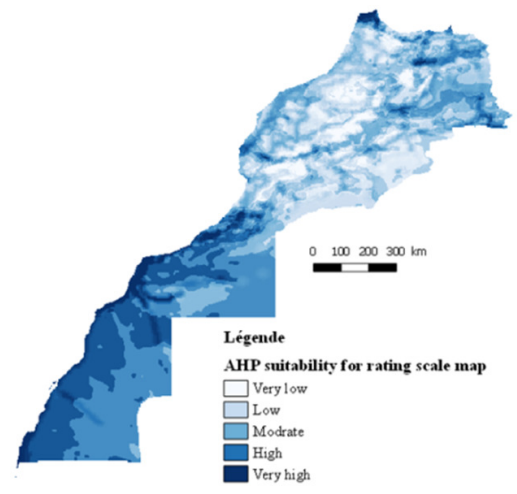

Fig. 8. AHP suitability for rating scale map

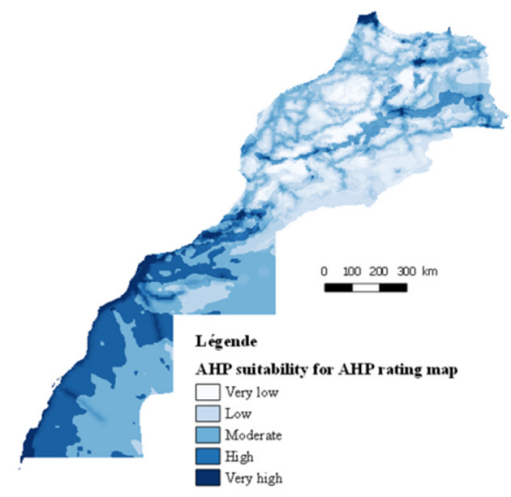

Fig. 9. AHP suitability for AHP scale map.

\section{B. AHP Results}

A weight for each criterion has been calculated using AHP methods to get information about the relative importance of each factor in modeling wind farm locations (Table V). Wind speed potential was rated as the most important criterion affecting wind energy development, so it was assigned a weight of 0.427. Slope, land use, distance from transmission lines, distance from roads and population density were assigned weight values of $0.207,0.089,0.175,0.068$, and 0.033 respectively.
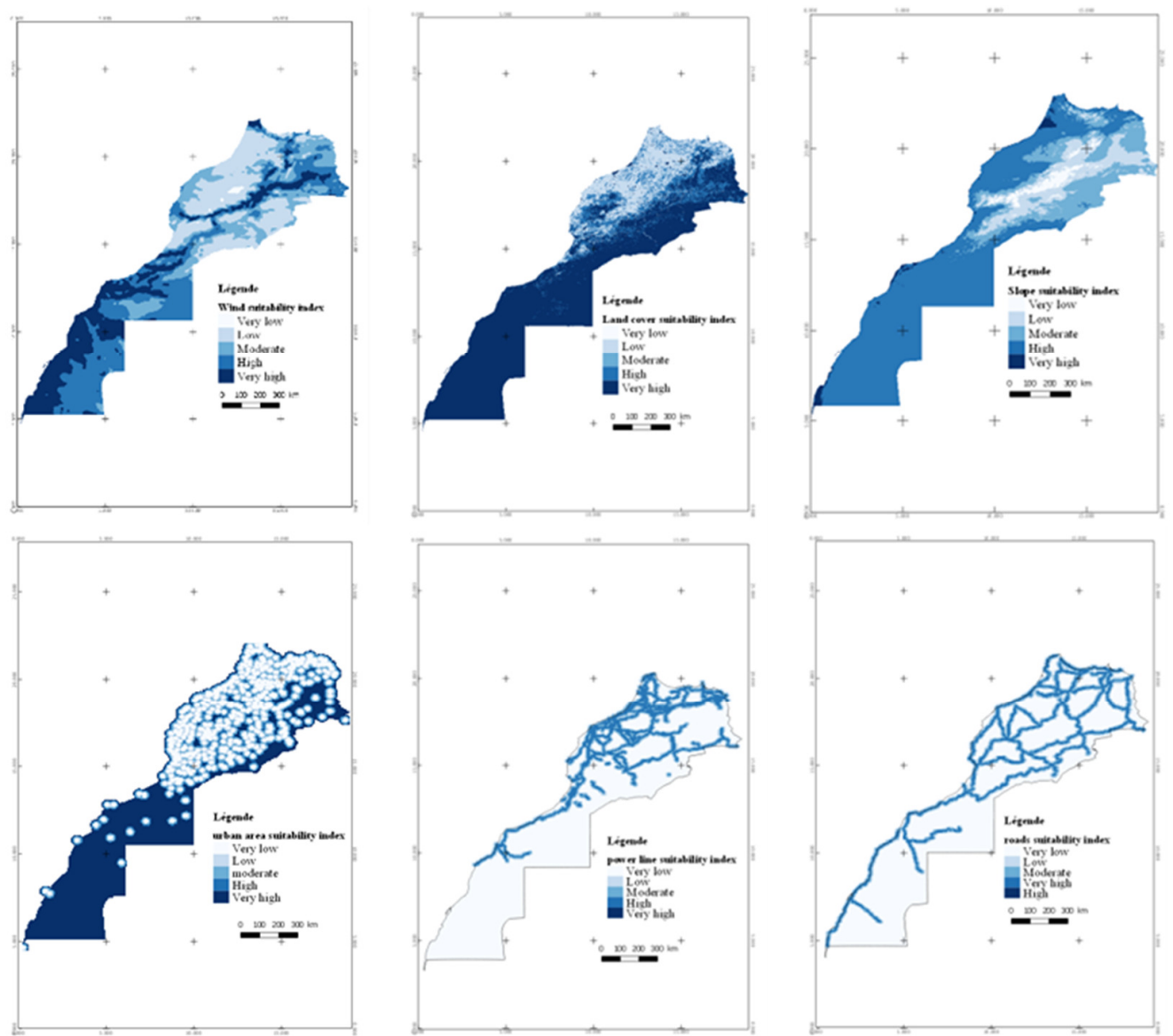

Fig. 10. Spatial patterns of suitability scores for each criterion. 

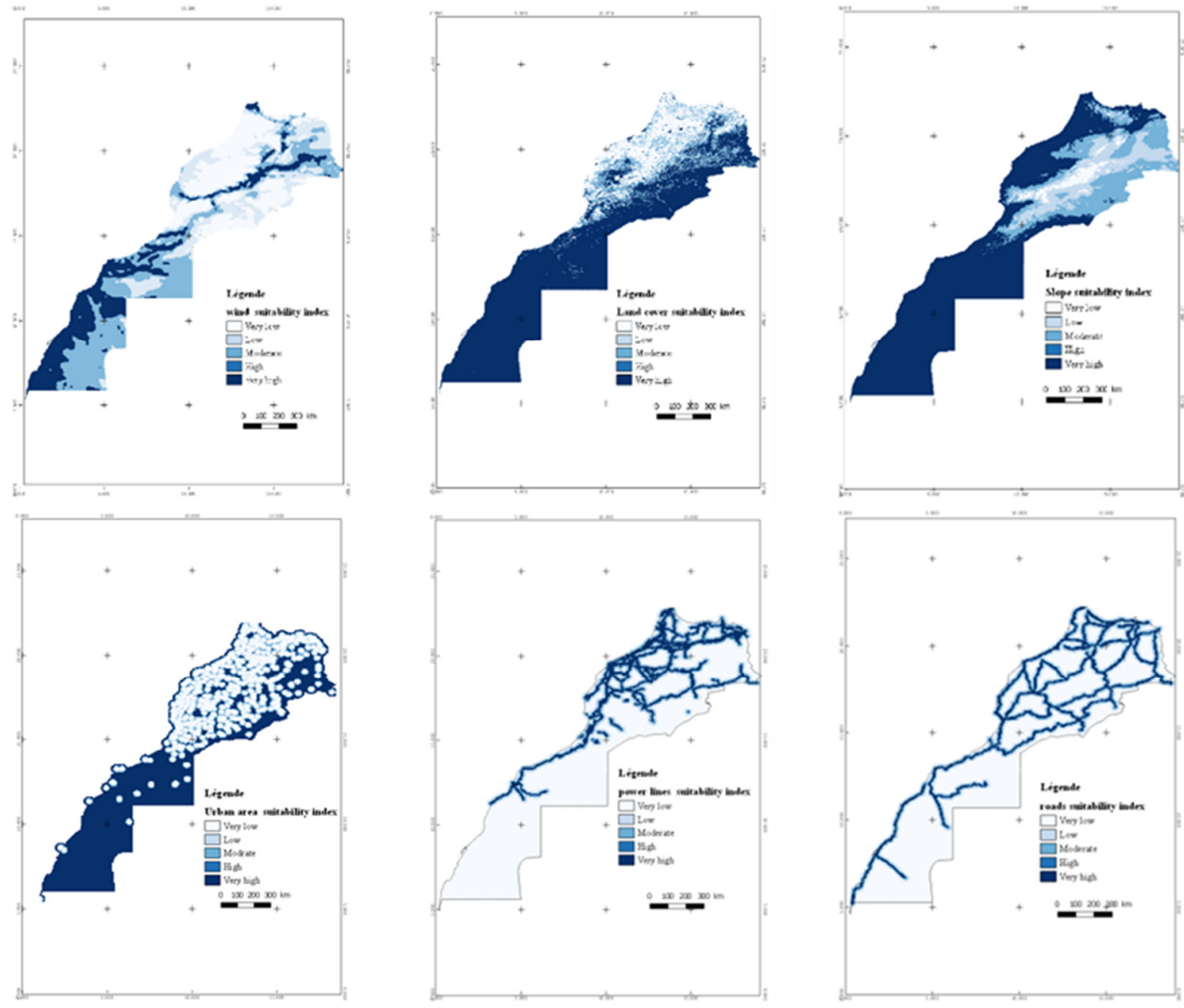

Fig. 11. Spatial patterns of AHP-suitability scores for each criterion.

All data layers were combined using AHP and were classified using a rating scale (Figure 10) and AHP scale (Figure 11) in QGIS. The final wind farm suitability map for the rating scale is shown in Figure 8 and for AHP scale is shown in Figure 9.

\section{DISCUSSION}

By comparing the AHP result, it was shown that wind speed and slope are the most important attributes with values of 0.43 and 0.21 , and land use, distance from urban places, distance from roads and distance from power lines followed with values of $0.09,0.03,0.07$, and 0.18 respectively. It was noted that the locations of existing wind farms in Morocco and the very high suitability locations for installing wind farms coincide.

\section{CONCLUSION}

Considering the growing demand for energy in Morocco and the global conspicuous attention on renewable energy sources, careful selection of energy investment projects and efficient use of resources is important. Multi-criteria decision making methods can be utilized to select an appropriate location for renewable energy generation. In this paper, the AHP method was employed. The weight of each of the six criteria was determined and was assigned to different map layers in GIS, with each layer representing one of the criteria. Wind speed and slope were found to be the most important criteria for wind farms positioning. Distances to transmission lines and roads are associated with wind energy development cost, whereas land use and proximal population density are associated with the environmental consequences. The objective of this study was to design a cartography of the wind potential of the Moroccan territory. To our knowledge, it is the first geographical study carried out in this sense, on the whole map of Morocco. The approach developed in this study will help stakeholders in the decision-making to discover the different classified areas in Morocco. Furthermore, it can be used to evaluate the suitability of operating projects. As future work, pertinent wind farm site suitability analysis can be conducted for specific regions in Morocco using different methods of MCDM. Different scenarios can be modeled and compared based on the chosen methods, which will determine the result of each method according to the same criteria and choose the best method for wind farm location.

\section{REFERENCES}

[1] M. H. Baloch, G. S. Kaloi, and Z. A. Memon, "Current scenario of the wind energy in Pakistan challenges and future perspectives: A case study," Energy Reports, vol. 2, pp. 201-210, Nov. 2016, doi: 10.1016/j.egyr.2016.08.002. 
[2] M. Hussain Baloch, D. Ishak, S. Tahir Chaudary, B. Ali, A. Asghar Memon, and T. Ahmed Jumani, "Wind Power Integration: An Experimental Investigation for Powering Local Communities," Energies, vol. 12, no. 4, Jan. 2019, Art no. 621, doi: 10.3390/en12040621.

[3] M. Z. Malik, A. Ali, G. S. Kaloi, A. M. Soomro, M. H. Baloch, and S. T. Chauhdary, "Integration of Renewable Energy Project: A Technical Proposal for Rural Electrification to Local Communities," IEEE Access, vol. 8, pp. 91448-91467, 2020, doi: 10.1109/ACCESS.2020.2993903.

[4] A. Miller and R. Li, "A Geospatial Approach for Prioritizing Wind Farm Development in Northeast Nebraska, USA," ISPRS International Journal of Geo-Information, vol. 3, no. 3, pp. 968-979, Sep. 2014, doi: 10.3390/ijgi3030968.

[5] A. Kumar et al., "A review of multi criteria decision making (MCDM) towards sustainable renewable energy development," Renewable and Sustainable Energy Reviews, vol. 69, pp. 596-609, Mar. 2017, doi: 10.1016/j.rser.2016.11.191

[6] E. Triantaphyllou, "Introduction to Multi-Criteria Decision Making," in Multi-criteria Decision Making Methods: A Comparative Study, E. Triantaphyllou, Ed. Boston, MA: Springer US, 2000, pp. 1-4.

[7] E. Triantaphyllou, Multi-criteria Decision Making Methods: A Comparative Study. . Boston, MA: Springer US, 2000.

[8] R. W. Saaty, "The analytic hierarchy process-what it is and how it is used," Mathematical Modelling, vol. 9, no. 3, pp. 161-176, Jan. 1987, doi: 10.1016/0270-0255(87)90473-8.

[9] Y. Ali, M. Butt, M. sabir, U. Mumtaz, and A. Salman, "Selection of suitable site in Pakistan for wind power plant installation using analytic hierarchy process (AHP)," Journal of Control and Decision, vol. 5, no. 2, pp. 117-128, Apr. 2018, doi: 10.1080/23307706.2017.1346490.

[10] W. Ho, "Integrated analytic hierarchy process and its applications - A literature review," European Journal of Operational Research, vol. 186, no. 1, pp. 211-228, Apr. 2008, doi: 10.1016/j.ejor.2007.01.004.

[11] "Wind energy," IRENA. https://www.irena.org/wind. (accessed Jul. 12, 2020).

[12] "Earthdata." https://earthdata.nasa.gov (accessed Jul. 12, 2020).

[13] “OpenStreetMap," OpenStreetMap. https://www.openstreetmap.org/ (accessed Jul. 12, 2020).

[14] "EarthExplorer - Home," EarthExplorer. https://earthexplorer.usgs.gov/ (accessed Jul. 12, 2020).

[15] Y.-C. Hu and Y.-L. Liao, "Utilizing Analytic Hierarchy Process to Analyze Consumers- Purchase Evaluation Factors of Smartphones," International Journal of Economics and Management Engineering, vol. 7, no. 6, pp. 1556-1561, Jun. 2013, doi: 10.5281/zenodo.1072078.

[16] J. Malczewski, GIS and Multicriteria Decision Analysis. Hoboken, NJ, USA: Wiley, 1998.

[17] B. Memon, M. H. Baloch, A. H. Memon, S. H. Qazi, R. Haider, and D. Ishak, "Assessment of Wind Power Potential Based on Raleigh Distribution Model: An Experimental Investigation for Coastal Zone," Engineering, Technology \& Applied Science Research, vol. 9, no. 1, pp. 3721-3725, Feb. 2019

[18] M. H. Baloch et al., "A Research on Electricity Generation from Wind Corridors of Pakistan (Two Provinces): A Technical Proposal for Remote Zones," Sustainability, vol. 9, no. 9, p. 1611, Sep. 2017, doi: 10.3390/su9091611.

[19] D. Pylarinos and I. Pellas, "Incorporating Open/Free GIS and GPS Software in Power Transmission Line Routine Work: The Case of Crete and Rhodes," Engineering, Technology \& Applied Science Research, vol. 7, no. 1, pp. 1316-1322, Feb. 2017.

[20] S. J. Carver, "Integrating multi-criteria evaluation with geographical information systems," International Journal of Geographical Information Systems, vol. 5, no. 3, pp. 321-339, Jan. 1991, doi: 10.1080/02693799108927858.

[21] J. Malczewski and C. Rinner, Multicriteria Decision Analysis in Geographic Information Science. Berlin Heidelberg: Springer-Verlag, 2015.

[22] A. Hajinezhad, S. Rahebi, and S. Abedi, "Biodiesel Production Potential from Native Tehran Oil Crops Using GIS," Engineering, Technology \& Applied Science Research, vol. 7, no. 6, pp. 2303-2307, Dec. 2017.
[23] H. I. Mohammed, Z. Majid, Y. B. Yamusa, M. F. M. Ariff, K. M. Idris, and N. Darwin, "Sanitary Landfill Siting Using GIS and AHP: A Case Study in Johor Bahru, Malaysia," Engineering, Technology \& Applied Science Research, vol. 9, no. 3, pp. 4100-4104, Jun. 2019.

[24] S. Das, "Geographic information system and AHP-based flood hazard zonation of Vaitarna basin, Maharashtra, India," Arabian Journal of Geosciences, vol. 11, no. 19, p. 576, Sep. 2018, doi: 10.1007/s12517018-3933-4.

[25] F. Elmahmoudi, O. E. Abra, A. Raihani, O. Serrar, and L. Bahatti, "GIS Based Fuzzy Analytic Hierarchy Process for wind Energy Sites Selection," in 2019 International Conference on Advanced Communication Technologies and Networking (CommNet), Apr. 2019, pp. 1-8, doi: 10.1109/COMMNET.2019.8742365.

[26] T. L. Saaty, Decision Making for Leaders: The Analytic Hierarchy Process for Decisions in a Complex World, New Edition 2001, 3rd Revised edition. Pittsburgh, PA: RWS Publications, 2012. 